\title{
Estados Unidos, las empresas transnacionales y el subdesarrollo: Una lectura desde Furtado
}

\author{
Gregorio Vidal \\ Universidad Autónoma Metropolitana, México \\ (iD) https://orcid.org/0000-0002-6305-4247 \\ vidal.gregorio@gmail.com
}

\section{Introducción}

En la introducción del libro Desenvolvimento e subdesenvolvimento, Celso Furtado destaca que en los años cincuenta y principios de los sesenta del siglo pasado la ciencia económica enseñada en las universidades de Europa y de Estados Unidos difícilmente ofrecía punto de partida alguno para abordar la materia del subdesarrollo.

La teoría de los precios, cuerpo central de la ciencia económica, estructurada dentro del marco de concepción del equilibrio general, excluía toda actitud mental dirigida a problemas de dinámica social... Toda insistencia en las diferencias estructurales hacia nacer la sospecha de una asimilación insuficiente del método científico de la economía (FURTADO, 1964. p. 5). 
El texto se publicó en Brasil en 1961 y reúne diversos trabajos realizados en los diez años previos con el objetivo de indagar en los problemas del subdesarrollo. A la fecha la propuesta de Furtado es plenamente vigente. El subdesarrollo permanece bajo otras formas e incluye a gran cantidad de países y territorios. Además, en las universidades, no solo de Europa y Estados Unidos, la ciencia económica que mayormente se enseña no ofrece la posibilidad para abordar los problemas de esos países y más ampliamente de la dinámica social en el conjunto de las sociedades capitalistas.

Al sintetizar el análisis realizado en diversos capítulos del libro Desenvolvimento e subdesenvolvimento, en particular lo expuesto en el capítulo IV, Furtado plantea que:

el subdesarrollo no constituye una etapa necesaria del proceso de formación de las economías capitalistas modernas. Es, en sí, un proceso particular resultante de la penetración de las empresas capitalistas modernas en las estructuras arcaicas. El fenómeno de subdesarrollo se presenta en formas variadas y en distintas etapas (FURTADO, 1964, p. 176).

Hay subdesarrollo con industrialización, con empresas transnacionales y amplios procesos de apertura financiera y económica que vinculan a ciertas economías con los procesos de internacionalización en curso desde hace décadas.

La acción de las empresas capitalistas en espacios no capitalistas es un dato sustantivo de la organización de la economía internacional y en tanto ello del comercio internacional. En este punto las propuestas de Furtado, como el conjunto de la escuela estructuralista latinoamericana, son una firme crítica a la teoría del comercio internacional fundada sobre los principios de las ventajas comparativas. En un texto presentado en la VI Conférence François Perroux, realizada en el Collège de France en Paris, en junio de 1994, intitulado "Retour à la 
vision globale de Perroux et Prebisch”, destaca que:

...un des corollaires de cette théorie, le commerce International $n$ 'est pas seulement un 'moteur de croissance' -il permet à tous les pays qui y participent d'utiliser plus rationnellement ses propres ressources -, mais serrait également un factor de réduction des disparités des niveaux de revenus entre pays (FURTADO, 2006, p. 18).

Sin embargo, refiriéndose a las aportaciones de Prebisch, observa que la evidencia existente permite concluir en sentido contrario, hay una concentración del ingreso engendrado por el intercambio internacional en beneficio de los países de nivel de productividad y salario real más elevado. "Prebisch déplaça la discussion du niveau des théorèmes d'avantages comparatifs à celui de l'observation des structures sociales au sein desquelles se forment les coûts et s'approprie l'excédent"' (FURTADO, 2006, p. 19).

En un texto publicado en portugués en 1967, al estar explicando el papel del comercio exterior en la dinámica de la economía mundial y refiriéndose al criterio de las ventajas comparativas concluye:

Desde un punto de vista teórico, la crítica esencial a la teoría del comercio internacional es idéntica a la que se le hace a la teoría estática del equilibrio general: establece los criterios de racionalidad de los agentes económicos en una situación cualitativamente distinta de la realidad. Al despreciar el proceso de acumulación, que es no sólo la fuerza motora del desarrollo sino que también constituye el puente que liga el presente con el futuro, la teoría del comercio internacional va mucho más lejos: más que simplificar exageradamente el proceso económico, lo desnaturaliza (FURTADO, 1974, p. 204).

Para los propósitos del texto enfatizo que la comprensión del subdesarrollo y su proceso implica una forma de conceptualizar las relaciones económicas y políticas internacionales. Es parte sustantiva de una explicación del sistema mundo de la economía y sociedad capi- 
talista. Como lo plantea Gerard de Bernis, en un texto que intituló: Furtado et l'économie mondiale, presentado en Paris en un coloquio internacional sobre las contribuciones de la obra de Celso Furtado:

...on restreint trop souvent la portée de l'œuvre de Celso Furtado quand on la présente simplement comme une théorie du seul développement, alors que son apport fondamental me paraît résider dans l'immersion du sous-développement dans l'univers des relations économiques internationales (DE BERNIS, 1998, p. 59).

Sin esta perspectiva la economía política internacional no cuenta con los medios para avanzar en diversos problemas sustantivos, desde la explicación del comercio internacional, hasta los desplazamientos de capital y la asimetría en las relaciones económicas y políticas entre países y sus estados nacionales, entre grandes empresas y entre algunas grandes empresas y ciertos estados nacionales. En el texto se analiza el papel de Estados Unidos, específicamente con relación a la dinámica de las sociedades en América Latina y las acciones de las empresas transnacionales en la economía mundial y en particular en América Latina, todo ello frente al problema de la creación de las condiciones del desarrollo.

\section{Capitalismo, industria y subdesarrollo}

La constitución de un núcleo industrial en la Europa del siglo XVIII modifica sustancialmente el comportamiento de la economía a nivel mundial. Dos aspectos relevantes de la nueva situación son: a) los factores causales- genéticos del crecimiento (afirma Furtado) pasan a ser endógenos del sistema económico; b) hay una relación esencial, una articulación del proceso de formación de capital con el desarrollo de la ciencia experimental. Esta economía industrial con 
origen en Europa se desarrolló en tres líneas. La primera se dio en la propia Europa occidental, provocando una desorganización de la economía artesanal precapitalista. Fue un proceso largo que considero el cuadro de las divisiones políticas de la anterior etapa mercantilista (FURTADO, 1964). La segunda línea de desarrollo fue la expansión de sus fronteras. Al respecto Furtado sostiene que

...ese desplazamiento de la frontera no se diferenciaba, básicamente, del proceso de desarrollo de la propia Europa, del que formaba parte, por así decirlo: las economías australiana, canadiense o estadounidense, en esa fase, eran simples prolongaciones de la economía industrial europea (FURTADO, 1964, p. 164).

Sin embargo, al serlo su expansión marca una forma específica de organización de la economía mundial.

La tercera línea de expansión de la economía industrial capitalista europea “....se realizó en dirección de las regiones ya ocupadas, algunas de ellas densamente pobladas, con sus sistemas económicos, de diversos tipos, pero todos ellos de naturaleza precapitalista” (FURTADO, 1964, p. 165). Las economías capitalistas se relacionan con esas regiones de manera diversa, teniendo en cuenta procesos de colonización que se prolongan en tiempo diferenciado. Con este proceso se completa una forma de articulación de la economía mundial que tiene en la asimetría una de sus características más importantes. También es notable la persistencia en esas regiones de formas de organización económicas no capitalistas. Furtado se refiera a la creación de estructuras hibridas, “...una parte de las cuales tendía a comportarse como un sistema capitalista, y la otra a mantenerse dentro de la estructura preexistente” (FURTADO, 1964, p. 165). Este tipo de economía constituye específicamente el fenómeno del subdesarrollo. Sin embargo, ello no implica mantenimiento de las estructuras preexistentes. Las 
empresas capitalistas están actuando en las regiones coloniales y antes coloniales; y, en ellas generan procesos de destrucción de formas no capitalistas modificando la dinámica económica en esos espacios. La acción de las empresas capitalistas en esas regiones y países generan diversos procesos que dan contenido al funcionamiento de la economía mundial.

Para el caso de las economías que reciben a las empresas capitalistas la diferencia sustancial tiene que ver con la ganancia obtenida y su lugar de realización. Furtado plantea que: “...la empresa capitalista que penetra en una región de vieja colonización y estructura económica arcaica no se vincula, dinámicamente, a esta última por el simple hecho de que la masa de ganancias generadas por ella no se integra en la economía local” (FURTADO, 1964, p. 167). En adelante las economías de estos países se modifican e incluso tienen procesos de industrialización, pero siempre se mantiene el problema de donde se realiza la ganancia obtenida y que relación hay entre los procesos que permiten alcanzar esos beneficios y el conjunto de la dinámica social. Un aspecto del problema es la relación entre las formas y el monto de los beneficios alcanzados por las empresas que operan en cada unos de esos países y el nivel de los salarios de amplios segmentos de la población y la propia incorporación de amplios grupos de la población a las formas de remuneración específicas de las economías capitalistas.

Refiriéndose al caso de Brasil, en los años en que dominaban ampliamente las actividades resultado de la producción de café y no obstante que “...la actividad monetaria era controlada, sobre todo por capitales nacionales” el resultado no era el mismo que en las economías industriales de la época. Las ganancias estaban ligadas al mercado externo y no tuvieron el mismo papel que en el caso de la economía 
industrial capitalista. "El elemento dinámico de la economía del café era la demanda externa, y no el volumen de inversiones realizadas en ella.” (FURTADO, 1964, p. 171). El tema clave es que las ganancias se reinvertían, aún cuando fueran realizadas por capitales del país, en tanto hubiese disponibilidad de tierras y de mano de obra atendiendo a la demanda externa, pero en un cierto punto "la experiencia demostró que los nuevos capitales allí formados tendían más bien a expatriarse que a buscar otros campos de aplicación dentro del sistema” (FURTADO, 1964, p. 171). La economía, aún cuando hay capitales del país en las actividades más dinámicas funciona a partir de determinaciones externas. Es un dato resultado de la especialización y la carencia de un núcleo interno que propicie el crecimiento. Para los efectos del texto explica en parte la operación de una economía internacional con base en una asimetría aún cuando se ha superado el colonialismo.

En las condiciones actuales, cuando en varios países de América Latina y otras regiones subdesarrolladas se ha implantado una actividad industrial, incluso diversa, el problema subsiste en tanto el elemento dinámico principal no se encuentra ligado al mercado interno. En el capitalismo de los años cincuenta, sesenta y setenta del siglo pasado, aún en economías como la de Brasil,

el proceso normal de desarrollo del grupo industrial sigue siendo la sustitución de importaciones ; de este modo, el elemento dinámico reside todavía en la demanda preexistente -formada principalmente por inducción externa - y no en las innovaciones introducidas en los procesos productivos, como ocurre en las economías industriales totalmente desarrolladas (FURTADO, 1964, p. 175).

Conforme se desarrollan estas economías la determinación externa es mayor o por lo menos se mantiene, en tanto involucra participación de empresas extranjeras en los segmentos más dinámicos de esas economías. 
Para el caso de la economía de México la investigación de Fajnzylber y Martínez Tarragó (1976) demostró que en el periodo posterior a la Segunda Guerra Mundial y hasta los años setenta las empresas extranjeras se ubicaron en los sectores más dinámicos de la economía de México, explicando en gran parte el avance de la industrialización y ocupando un lugar clave en la dinámica del mercado interno. La implantación de las empresas transnacionales se presenta con gran vitalidad después de la Segunda Guerra Mundial, destacando las firmas estadounidenses y el proceso incluye la venta de empresas manufactureras que estaban en manos de capitales del país (VIDAL, 1996).

Refiriéndose al conjunto de América Latina, en particular en el periodo que va de 1950 a los primeros años de la década del setenta concluye:

Los datos presentados ponen de manifiesto que la participación de grupos extranjeros en el desarrollo reciente de América Latina es mucho menos un fenómeno de cooperación financiera, que de control de actividades productivas por parte de grupos que ya venían abasteciendo el mercado por medio de exportaciones (FURTADO, 2001, p. 241).

Al igual que en el caso de la economía exportadora de materias primas, aún cuando hay participación de capitales del país las ganancias en parte se realizan en el extranjero. Además como destaca en Desenvolvimento e subdesenvolvimento, "la estructura de precios en el sector industrial ligado al mercado interno, tiende a asemejarse a la que prevalece en los países de elevado grado de industrialización y exportaciones manufactureras” (FURTADO, 1964, p. 176). Al operar bajo estas condiciones las empresas realizan inversiones que no necesariamente permiten una importante y rápida transformación de la estructura económica y menos aún la absorción del sector de subsistencia. Así se consolida la heterogeneidad estructural como otro de 
los rasgos del subdesarrollo que en parte se explica por la relación de las economías subdesarrolladas con la economía mundial.

En años recientes, con el avance de las corporaciones transnacionales y los procesos de apertura de las economías la determinación externa de la estructura de precios es mayor, como también la realización de las ganancias afuera de las economías subdesarrolladas. En este contexto una mayor industrialización e incluso un aumento de las exportaciones manufactureras desde economías como las de México es un dato de profundización del subdesarrollo y de la heterogeneidad estructural. También es parte de la explicación de la relación de la economía de México, como la de otros países de América Latina, con la economía internacional.

\section{Estados Unidos y América Latina}

En la introducción del libro intitulado Os ares do mundo, publicado en 1991, Furtado destaca que inmediatamente después del golpe de Estado en Brasil en 1964, al salir del país le fue posible retomar la actividad intelectual en el ámbito de América Latina. No obstante la experiencia en Brasil le había convencido que era imprescindible “...una mejor comprensión de las transformaciones que estaban ocurriendo en los Estados Unidos, puesto que ese país había asumido plenamente el papel de centro mundial de poder” (FURTADO, 1993, p. 11). Para América Latina era un tema sustantivo, en tanto necesario para comprender la propia dinámica de la economía en los diversos países de la región. En palabras de Furtado:

La fuerza gravitacional que ese centro [Estados Unidos, gobierno, empresas transnacionales. GV] ejerce sobre los países latinoamericanos había crecido tanto, que se había vuelto imposible captar el sentido de lo que ocurría en ellos si no disponíamos de hipótesis res- 
pecto al comportamiento del sistema de poder estadounidense (FURTADO, 1993, p. 11).

A partir de esta observación Furtado se plantea tener una estancia de cierto tiempo en Estados Unidos, realizando el mismo el estudio de esa sociedad.

Sus planes tuvieron que cambiar en poco tiempo atendiendo a hechos políticos producto; por un lado, de la acción de la dictadura brasileña, y, por otro del clima de la guerra fría que “...llevaría al gobierno Washington a apoyar el status quo social y combatir muchos movimientos cuyo objetivo era promover la simple modernización de las estructuras sociales, los cuales pasaban a ser vistos como conspiraciones tendientes a reforzar a su adversario en la guerra fría” (FURTADO, 1993, p. 115). Por ello se vio obligado a desplazarse a París sin concluir sus investigaciones. Sin embargo, años después decide publicar bajo el título del Interregno norteamericano lo esencial de ese material de investigación. Sus observaciones dan cuenta de un análisis de la economía y sociedad a escala mundial, considerando el papel hegemónico de Estados Unidos. Para América latina se configura un escenario particularmente negativo.

En el momento en que urgía introducir reformas sociales para evitar que una industrialización tardía viniese a agravar las tendencias estructurales a la concentración del ingreso, se reforzaba la rigidez del sistema de dominación. Esa política llevó al gobierno estadounidense a prestigiar, cuando no a fomentar, la instalación de dictaduras militares en la mayoría de los países latinoamericanos (FURTADO, 1993, p. 115-116).

La situación en América Latina debía considerar también, como analizó más adelante, la acción de las empresas extranjeras en la región y los cambios en los sectores empresariales de los diversos países 
del área. Es en este escenario que se llega a los años setenta y ochenta cuando la hegemonía estadounidense presenta algunas grietas y la economía mundial penetra en un periodo de tensiones mundiales sin precedente. Furtado plantea el problema en su complejidad al referirse al proceso de globalización en el texto O Capitalismo Global, publicado en 1998. Señala que las tensiones estructurales "se manifestam desde o começo dos anos 80 nos países do Terceiro Mundo sob a forma de brusca elevação das taxas de juros dos mercados internacionais e de intensa drenagem de capitais para os Estados Unidos” (FURTADO, 1998a, p. 35). También existe un amplio proceso de destrucción y reconstrucción de las economías del este europeo a la vez que avanza el proyecto de integración en Europa occidental. La globalización es un momento de grandes tensiones que implica la emergencia de nuevas fuerzas sociales, a la vez que algunas otras cambian.

La transformación en curso de la economía internacional plantea el problema de la hegemonía estadounidense, su fortaleza y la emergencia de otros espacios de poder. Para América Latina es un dato relevante, dada la preeminencia del poder estadounidense en la región. Furtado destaca que por un lado "o processo atual de globalização a que assistimos desarticula a ação sincrônica dessas forças que garantiram no passado o dinamismo dos sistemas econômicos nacionais” (FURTADO, 1998a, p. 29). Furtado se refiere a la interacción entre la innovación técnica por un lado y por otro a la expansión del mercado que crece junto con la masa salarial, todo ello en el espacio del capitalismo desarrollado. El primero se refiere a la acción de los empresarios en la búsqueda de la maximización de sus beneficios y el segundo se vincula con la acción de diversas fuerzas sociales que luchan por la elevación de sus salarios. Es parte sustantiva del crecimiento de los años de la segunda posguerra hasta principios de la década de los años 
setenta. Es parte del proceso que permite el mantenimiento de la hegemonía estadounidense y la lucha contra el adversario en el contexto de la guerra fría. Sin embargo, el desarrollo de ese sistema que implica una creciente operación a nivel global de un grupo de grandes empresas que se apoyan cada vez más en los mercados externos para crecer, desarticulan la acción sincrónica de esas fuerzas que en pasado garantizaban el dinamismo de los sistemas económicos nacionales.

El resultado en curso es que:

A estrutura internacional de poder evolui para assumir a forma de grades blocos de nações-sedes de empresas transnacionais que dispõem de rico acervo de conhecimentos e pessoal capacitado...Na dinâmica desse sistema, prevalecem as forças tendentes a reproduzir a atual clivagem desenvolvimento/subdesenvolvimento (FURTADO, 1998a, p. 38).

Después la crisis de la deuda externa, con la aplicación en la mayor parte de los países de América Latina de políticas económicas fundadas en el ajuste fiscal avanza una transformación en esas sociedades que revela la significación de Estados Unidos en la región. Al ajuste fiscal se prolonga a lo largo de los años ochenta, a la vez que se realizan diversas renegociaciones de la deuda externa que hacen parte de una transformación estructural de las economías de la región.

La gravitación de la deuda y la administración de su cumplimiento en América Latina superan el estadio financiero y de comercio exterior al que ciertos estudios sobre la crisis pretenden confinarla, y comprometen asimismo ciertas coordenadas generales del empleo interno del excedente o la acumulación de capital (LICHTENSZTEJN, 1990, p. 169).

Lo que se imponen son medidas de política económica formalmente ejecutadas para controlar la inflación, pero que en los hechos son 
parte de una internacionalización de la dinámica económica de los países del área.

Manteniendo el ajuste fiscal se llevan a cabo otras medidas en el ámbito de la política monetaria, siempre en acuerdo con las recomendaciones del Fondo Monetario Internacional (FMI) y el Banco Mundial (BM). Posteriormente se añade la apertura comercial y la liberalización de la cuenta de capitales de la balanza de pagos. Más reformas denominadas estructurales se agregan en materia de eliminación de límites a la inversión extranjera, desregulación en la economía, supresión de subsidios y otras disposiciones para reducir la acción estatal en algunos espacios de la economía y las privatizaciones. Ese conjunto de políticas y transformaciones en leyes e instituciones que modifican la dinámica de las economías de la región a partir de la acción de los gobiernos y el conjunto del poder público es lo que se caracterizó como la agenda del Consenso de Washington (CW). Este conjunto de políticas y reformas es impulsada por el FMI, el BM y el poder ejecutivo de Estados Unidos, pero también se suman el Banco Interamericano de Desarrollo (BID) y algunos miembros del Congreso de Estados Unidos con intereses en América Latina (WILLIAMSON, 1990, p. 1).

Durante los años noventa y al inicio de la década pasada las propuestas impulsadas por las fuerzas que defienden el CW, con base en la continuidad del ajuste fiscal, se siguieron aplicando y se planteó una segunda generación de reformas estructurales que implicó cambios en los mercados laborales con el objetivo de una mayor flexibilización, no obstante los altos niveles de precariedad laboral y el amplio grupo de ocupación informal que caracteriza a los países de la zona. También se mantuvieron las privatizaciones, que en los hechos permitieron la ampliación de actividades de las empresas transnacionales en la re- 
gión, incluidos los servicios públicos. Un grupo de corporaciones que recién había iniciado su internacionalización avanzaron en los mercados de América Latina. Son los casos entre otras de Repsol, Endesa y Telefónica con matriz en España. Con matriz en Estados Unidos fueron MCI, Bell South, Enron y AES. Todas ellas realizaron adquisiciones de empresas privatizadas y en otros casos compraron firmas que tenían poco tiempo de haber sido vendidas por el sector público (VIDAL, 2001; VIDAL, 2009).

La ejecución de la agenda del Consenso de Washington es parte de la propuesta encabezada por el gobierno estadounidense y algunos segmentos de los grandes capitales con matriz en Estados Unidos para avanzar en la determinación de la dinámica social en la región. Furtado observa que con el avance de la globalización "as economias latino-americanas estarão submetidas a pressões crescentes para desregular os seus mercados, o que acarretará efeitos diversos em função do grau de heterogeneidade de suas estruturas sociais” (FURTADO, 1998a, p. 32).

Acompañando las reformas estructurales el gobierno estadounidense plantea diversas propuestas de organización regional de los mercados que considera acuerdos bilaterales de inversión y lo que denomina tratados de libre comercio. Es el caso del Tratado de Libre Comercio de América del Norte (TLCAN) que incluye a México, Canadá y Estados Unidos. Sin discutir la naturaleza y el alcance del TLCAN, que ha sido objetado por el gobierno estadounidense, para los propósitos de este texto conviene tener en cuenta que es un acuerdo que además del ámbito del comercio incluye un amplio capítulo sobre inversiones y las reglas para que las empresas tengan un trato semejante en toda la zona. La transformación de la economía en México ha implicado que se acentúa la relación con la economía estadounidense, 
además como analizó en otro texto junto a la eliminación de restricciones para que firmas extranjeras puedan ser propietarias en México, para una parte de ellas la localización de inversiones en el país no tiene como objetivo cubrir el mercado interno. Su objetivo es el mercado estadounidense, pero también sus medios de financiamiento se han internacionalizado; sin que por otro lado se observe la aparición de un grupo relevante de compañías con matriz en México que a partir de sus actividades en el país tenga un proceso de internacionalización (VIDAL, 2015a). La determinación estadounidense es de gran significación, constituyéndose en un dato estructural de gran alcance en la economía del país, pero también haciendo parte de los cambios en la dinámica de las grandes fortunas con base en el país. La acción por parte del gobierno estadounidense es clave para entender proyectos como el TLCAN. Al respecto Furtado señaló:

Tal situação (refiriéndose a los cambios en la economía de Estados Unidos, la internacionalización de los mercados financieros y el déficit sostenido en a balanza de pagos de ese país) está conduzindo a modificações importantes nas relações internacionais desse país, como exemplifica a recente criação da zona de livre câmbio, englobando os mercados dos Estados Unidos, Canadá e México. As indústrias norte-americanas poderão, assim, recuperar a competitividade internacional, pois os salários monetários no México não passam de uma décima parte dos que prevalecem nos Estados Unidos (FURTADO, 1998a, p. 30).

En línea con ese objetivo, para recuperar competitividad y establecer un mayor predominio de sus intereses, el gobierno de Estados Unidos presentó y desarrollo una propuesta que con base en los elementos sustantivos del TLCAN incluía al conjunto de los países de América. Fue el proyecto para crear el Área de Libre Comercio de América (ALCA). Como señaló Furtado, considerando específicamente el TLCAN, “a experiência de integração com o México, excluindo a mobili- 
dade da mão-de-obra, servirá de paradigma a um prometo mais amplo, capaz de abranger todo o Hemisfério” (1998a, p. 30). El proyecto se desarrollo casi inmediatamente, hacia el final de los años noventa y en la primera mitad de la década pasada. Sin embargo, en varios países de la región habían triunfado en procesos electorales gobiernos que desde diversas posiciones y sin compartir una agenda común se distanciaran de las propuestas del FMI y el BM y más ampliamente de la agenda del Consenso de Washington. Según los términos que adoptan los propios gobiernos, son lo que se establecen en Argentina, Bolivia, Brasil, Ecuador, Venezuela y Uruguay en un periodo que va de 1999 en Venezuela, hasta 2007 en Ecuador. En ese escenario apareció en la región una disputa entre dos posiciones que ponía de manifiesto la significación de Estados Unidos en la región. Un punto relevante de la disputa fue en la IV Cumbre de las Américas efectuada en Mar del Plata, en 2005.

La iniciativa para acordar el ALCA se formalizó en la primera Cumbre de las Américas, realizada en diciembre de 1994 en Miami, contando con la participación de presidentes o jefes de gobierno de 34 naciones del continente. El calendario previa concluir las negociaciones en el año 2005. Sin embargo, en Mar de Plata se observaron dos posiciones. Un grupo de gobiernos entre los que estaban Estados Unidos, Canadá y México, reconocían los avances y la posibilidad alcanzar un Acuerdo ALCA, dirigido a la expansión de los flujos comerciales; mientras otros - incluyendo en ese grupo a los gobiernos de Argentina y Brasil - sostenían que no estaban dadas las condiciones para lograr un acuerdo de libre comercio equilibrado y equitativo, en particular que tome en cuenta los niveles de desarrollo y tamaño de las economías (IV CUMBRE DE LAS AMÉRICAS, 2005, p. 4-5). En el discurso inaugural de la IV Cumbre el Presidente de Argentina, 
Néstor Kirchner, sostuvo que hay evidencia del fracaso de las propuestas del Consenso de Washington y criticó las políticas de ajuste estructural y endeudamiento externo. Sobre la propuesta del ALCA señaló:

La integración posible será aquélla que reconozca las diversidades y permita los beneficios mutuos. Un acuerdo no puede ser un camino de una sola vía de prosperidad en una sola dirección. Un acuerdo no puede resultar de una imposición con base en las relativas posiciones de fuerza...( )...La integración será posible en la medida que se atiendan las asimetrías existentes y si las negociaciones satisfacen los intereses fundamentales de cada país (KIRCHNER, 2005, p. 4).

De ese momento a la fecha, en algunos países el proyecto de transformación con base en la continuidad del ajuste fiscal y la ejecución de la agenda del Consenso de Washington se mantuvo. Pero en otros el distanciamiento también tuvo continuidad. No obstante, hoy se observan algunos cambios importantes. Además de la disputa en curso en Venezuela, en Argentina y Brasil los gobiernos han cambiado y se ha producido el retorno de las propuestas de liberalización comercial $\mathrm{y}$ financiera, nuevas privatizaciones, reformas laborales regresivas y otras medidas que se ajustan con los intereses que defienden el FMI, el BM, el gobierno estadounidense y algunos congresistas de ese país con la mirada puesta en la región. La determinación estadounidense como la observará Furtado se mantiene y en diversos sentidos cuenta con fuertes apoyos en segmentos de los grandes capitales de la región. También se suman funcionarios del sector público, diversos círculos académicos de América Latina y medios de comunicación importantes. El hecho de la dependencia cultural se manifiesta con contundencia. 


\section{Empresas transnacionales y estructuras de poder en los países de América Latina}

En 2016 las exportaciones que realizan las filiales en el extranjero de empresas transnacionales (ETN) equivalen a $33.3 \%$ del total de exportaciones de bienes y servicios. Son varios lustros en que se alcanzan las mismas cifras. En 1990 el porcentaje fue de 32.6\%. Es en la década de los años ochenta del siglo pasado cuando las exportaciones realizadas por las filiales crecen a un ritmo mayor que las exportaciones totales. En 1982, con base en datos del Informe sobre las inversiones extranjeras de UNTAD de 2009, el coeficiente fue de 26.5\%. En el periodo de 1986 a 1990 el crecimiento promedio anual de las exportaciones de las filiales en el extranjero de ETN fue de $22.2 \%$, mientras las exportaciones totales crecieron en $11.6 \%$ (UNTAD, 2009, p. 18). El mayor peso de las exportaciones de filiales de ETN en el comercio mundial es un dato entre otros de los cambios que registran en su operación estas empresas.

En los años noventa las exportaciones realizadas por las filiales en el extranjero de ETN crecen a un ritmo semejante al de las exportaciones totales, manteniéndose hasta la fecha el coeficiente en torno al 33 por ciento. Las exportaciones de las filiales se realizan a otras empresas de la misma compañía o a la matriz, por lo que deben considerarse como transacciones intra firma, que hacen parte de las nuevas formas de producción de las ETN. Son transacciones que no constituyen comercio alguno y como otras actividades de intercambio en las compañías al interior de un mismo país no participan en procesos de precios definidos a partir de métodos directos de competencia. Por tanto son un elemento constitutivo relevante de las transacciones internacionales que no está sujeto a la formación de precios en los 
mercados y que tampoco es el resultado de ventajas comparativas a partir de la dotación de factores.

Otro dato que hace parte de la modificación en la inversión extranjera y propiamente en la acción de las ETN a nivel mundial es la participación de las filiales en el extranjero en el producto a nivel mundial. En la década de los años ochenta el producto o valor añadido por las filiales extranjeras de las ETN crece a tasas mayores que el PIB. Del año 2000 a la fecha, con base en información de UNCTAD, el valor añadido o producto de las filiales de ETN en el extranjero ronda el 10\% del PIB mundial. Es una cifra que se distribuye muy desigualmente en el conjunto de la economía mundial y que implica una diversa influencia en esos países de la producción por cuenta de las ETN. El dato relevante es que la producción realizada en esos países no se articula necesariamente con el conjunto de cada economía y tampoco es necesariamente para ser vendida en esos mercados. Es un dato más de las formas contemporáneas de internacionalización de las actividades de las ETN, en las que la deslocalización de una parte de la producción es significativa.

A finales de los años setenta Furtado reflexionaba sobre el avance de las ETN y los cambios en el orden internacional. Se observaba una mayor concentración del ingreso en los países ricos, pero también “el control creciente de las actividades económicas en los países pobres por empresas que operan a partir de los países ricos” (FURTADO, 1993, p. 294-295). Furtado agrega dos elementos que completan la acción de estas empresas: a) la canasta de productos que ofrecen refleja el grado de acumulación y nivel de ingreso de los países ricos; y, b) su crecimiento procura homogenizar los mercados y con ello ignoran las disparidades del poder adquisitivo de las poblaciones. En los años siguientes el avance de las ETN refuerza estos hechos paro tam- 
bién da origen a otras formas de control creciente de las actividades económicas y de fragmentación en las economías subdesarrolladas en las que actúan.

La dimensión del avance de las ETN se puede observar al considerar el crecimiento de los activos de las filiales en el extranjero. Comparado con el PIB los activos de las filiales equivalen en 1982 al $17.02 \%$. Al terminar esa década en el año 1990 representan 19.6\%. Durante esa década hay un notable incremento alcanzando la cifra de 66.2\% del PIB global. En los años siguientes siguen creciendo y la crisis financiera y del crédito y la gran recesión no implica que cesen las inversiones en el extranjero de las ETN. En el año 2010 estos activos son equivalentes a 123.9\% del PIB y en 2016 alcanzan la cifra de 149.9\% (UNCTAD, 2001, 2009, 2013 y 2017). Furtado destaca que desde los años setenta se apreciaba que en América Latina había avanzado con fuerza la implantación de un notable grupo de conglomerados estadounidenses. Estos conglomerados se ubican en las industrias dinámicas.

Aun cuando los estudios son introductorios, existe evidencia de que las empresas extranjeras -en su mayoría conglomerados americanos - controlan de un 50 a un 75 por 100 de la industrias dinámicas, esto es, de las industrias líderes en el proceso de desarrollo de América Latina (FURTADO, 1971, p. 57)

Controlando las actividades de más rápida expansión y, en tanto ello, orientando el proceso de acumulación Furtado señala “es menester preguntarse hasta qué punto es adecuado utilizar el concepto de sistema económico nacional en el análisis de tales economías” (FURTADO, 1971, p. 57).

En la primera parte del texto de Fajnzylber y Martínez Tarragó se analiza la expansión de las ETN después de la Segunda Guerra Mun- 
dial y hasta comienzos de los años setenta. Se destaca la preponderancia de las empresas con matriz en Estados Unidos, el peso creciente en el comercio internacional, con lo que los autores denominan comercio cautivo o comercio intrafirma. También se destaca el comercio cautivo de tecnología proporcionalmente más importante que el de bienes. En línea con los planteamientos de Furtado, los autores destacan que

la concentración creciente del flujo de bienes de capital, en los cuales se incorpora una proporción importante de progreso técnico, entre el grupo de países proveedores de tecnología, conduce a prever que cada vez en mayor medida serán las condiciones técnico-económicas que prevalecen en esos mercados, las que orienten y estimulen el esfuerzo de innovaciones y progreso técnico que se genera en esos países (FAJNZYLBER Y MARTÍNEZ TARRAGÓ, 1976, p. 135)

Cambios tecnológicos, innovaciones que se requieran en los países en que actúan las filiales no han sido promovidos ni lo serán por estas firmas.

La investigación de Fajnzylber y Martínez Tarragó demuestra que en la economía de México de los años setenta hay un alto nivel de concentración económica en el conjunto de la industria, incluso ligeramente superior a la Estados Unidos en esa época. Las ETN se ubican preferentemente en los sectores de mayor concentración y generan una proporción mayoritaria en esos sectores. Las filiales de las ETN son de un tamaño medio mayor que las grandes firmas del país; además estas filiales son las más dinámicas. Ellas están definiendo las características principales del sistema industrial en el país (FAJNZYLBER Y MARTÍNEZ TARRAGÓ, 1976, p. 354-371).

Considerando la situación de Brasil a finales de los años sesenta y principios de los setenta, pero teniendo en cuenta los elementos comunes con otras economías de América Latina, Furtado avanza en la caracterización del capitalismo de esos años, en particular del capi- 
talismo del subdesarrollo. Un elemento clave se refiere al sistema de decisiones en el capitalismo de grandes unidades. El análisis de la economía internacional debe considerar ese hecho. La competencia entre las firmas se ha desplazado del espacio de los precios. Aparece el tema de la innovación y la creación de demanda. Son esas grandes unidades económicas las que encabezan la internacionalización y explican gran parte de las transacciones de bienes entre países, como lo destacó líneas antes. Furtado tiene presente el análisis de Galbraith (1967) a propósito del papel de las grandes empresas en el comportamiento de conjunto de la economía de Estados Unidos. Antes señalé que estas grandes unidades económicas están en los países de América Latina ocupando un espacio sustancial en la dinámica de sus economías. El punto es:

Si las grandes empresas lideran los mercados y planifican a medio y largo plazo importantes sectores de la actividad económica, es evidente que los beneficios que ellas obtienen son, grosso modo, determinados por ellas mismas, lo que es hecho dentro de ciertas reglas, teniendo en cuenta la presión salarial, la política fiscal y los planes de expansión de la empresa en cuestión (FURTADO, 1971, p. 158)

Esto es rigurosamente cierto para un reducido grupo compañías. Al hacer esto condicionan a otras empresas y generan elementos clave de la dinámica de la economía. Para el caso de los países de América Latina el tema sensible es que estas firmas actúan desde el exterior y en años recientes, con los procesos de apertura económica y la propia internacionalización, los planes de expansión y las decisiones de inversión de esas firmas son un hecho externo. Pero también, la incorporación del avance tecnológico, el tipo y características de las innovaciones añadidas son un resultado de las decisiones de las ETN, por lo menos en el núcleo dinámico de la acumulación de capital. Teniendo en cuenta que hay retención por la gran corporación de los frutos 
del progreso tecnológico y control por grupos extranjeros de las empresas que actúan en los sectores de vanguardia, Furtado sostiene que “...se impone la conclusión de que tanto la industrialización como la asimilación del progreso tecnológico favorecen el control del sistema por grupos no nacionales” (FURTADO, 1971, p. 163).

Desde finales de la década de los años ochenta a la fecha la economía en México tiene una significativa transformación. Un dato del cambio es el notable incremento del comercio exterior como proporción del PIB y la composición mayoritaria del mismo por productos de la industria manufacturera. Como analizó en otro texto (VIDAL, 2015b), gran parte del comercio tiene como destino el mercado estadounidense, pero también se trata de exportaciones con alto contenido importado. Además, aumenta la cantidad de maquinaria y equipo importado en el total de la inversión bruta fija. Desde comienzos de la década pasada la inversión en maquinaria y equipo manufacturada en el país equivale entre 2.3 y 2.7 \% del PIB, mientras la importada es superior al 4.5\% en gran cantidad de años de ese periodo (VIDAL, 2015b). Se establece una plataforma exportadora en algunas industrias manufactureras que es realizada en su mayor parte por un reducido grupo de ETN. El destino es la economía de Estados Unidos. Como concluyó en el texto sobre las transformaciones de la economía en México:

Many have argued that one of the positive results of the economy's transformation is the integration of international trade and investment flows, and that this incorporation would enhance the wellbeing of the national population. However, as discussed above, there is no integration of the economy into international trade or investment flows. Linkages are only created within a small group of activities, all led by transnational firms, which only consider the conditions of the U.S. market in making investment decisions. These firms have shifted part of their production to Mexico in order to compete in the U.S. market, and products made in Mexico do not pri- 
marily target the domestic market. There is no relationship between the expansion of these activities and the composition of aggregate demand and, therefore, the expansion of the domestic market is hindered (VIDAL, 2015b, p. 80).

El desarrollo de la industria, la implantación de una plataforma exportadora en algunas actividades manufactureras y la incorporación de nuevas tecnologías no esta vinculado con el desempeño del mercado interno y menos aún propicia un amplio crecimiento de la economía en México. La implantación de este segmento dinámico en la economía del país implica una fragmentación mayor en el conjunto de la economía. Crece la desarticulación en el sistema económico, al punto que se crea infraestructura para realizar la conexión con el exterior aún cuando esto contribuya a mantener o aumentar la dislocación en diversas partes del territorio del país.

En el texto Criatividade e dependência na civilização industrial, después de explicar como se modifica el ejercicio del poder en una sociedad que se globaliza y el papel de las grandes empresas en ese contexto, señala algunos cambios relevantes para explicar la situación de las economías de América Latina. Por ejemplo, el valor o precio al que se remunera la mano de obra es un fenómeno social que se define en el ámbito de los sistemas económicos nacionales, lo que es válido incluso en la Unión Europea. "Se comparamos sistemas econômicos contemporâneos, constatamos que o valor da mão-de-obra varia em função da estrutura interna de dominação (a forma como é apropriado e utilizado o excedente social) e do nível de acumulação” (FURTADO, 2008, p. 51-52). Con la producción por empresas transnacionales, como la que realizan firmas de Estados Unidos en varios países, se integran en un mismo proceso productivo recursos que pertenecen a sistemas económicos diferentes. Pero no hay homogenización entre los recursos utilizados, menos en el caso de las remuneraciones 
a los asalariados. También la empresa que tiene una actividad transnacional, con filiales y compañías en diversos países “administra um sistema de preços que enquadra uma série de transações internacionais efetuadas dentro do grupo" (FURTADO, 2008, p. 48). Actuando en un espacio multinacional se abre la posibilidad que por medio de la administración de precios se transfieran recursos a la matriz. Todo ello es expresión de lo que significa para los países de América Latina el avance de una economía en la que las relaciones internacionales están gobernadas por un grupo de empresas transnacionales con matriz en algunos países desarrollados, significativamente Estados Unidos, y que actúan con el apoyo de sus respectivos Estados.

\section{A manera de conclusión: Las transnacionales y la continuidad del subdesarrollo}

La explicación del subdesarrollo es un aporte relevante en los estudios de Celso Furtado. Pero lo específicamente significativo es que la explicación del subdesarrollo se da en el espacio de las relaciones económicas y políticas internacionales. En Furtado hay una teoría, una economía política de las relaciones económicas internacionales. Es, como se analiza en el texto, el resultado de una crítica sustancial a la teoría del comercio internacional de las ventajas comparativas. $\mathrm{Al}$ explicar la aparición del subdesarrollo y su avance, la acción de las empresas capitalistas es un aspecto imprescindible, desde la propia difusión de la industrialización.

Se considera el subdesarrollo como una creación del desarrollo, esto es, como consecuencia del impacto, en un gran número de sociedades, de procesos técnicos y de formas de división del trabajo irradiados por un número reducido de sociedades ya insertadas en la revolución industrial en la fase inicial de ésta, o sea, hacia fines del 
siglo pasado (FURTADO, 1971, p. 15).

Para diversos países de América Latina, el avance del subdesarrollo implicó en gran parte del siglo XX industrialización. Sin embargo, las formas de la industrialización y los actores sociales que condujeron el proceso implicaron el mantenimiento del subdesarrollo. Bajo esas condiciones el estudio de la economía y la sociedad estadounidense se tornaron relevantes, dada la determinación que gobierno y empresas de ese país tuvieron en la dinámica de América Latina. Como se plantea en el texto, el estudio de Estados Unidos era imprescindible dado “...que ese país había asumido plenamente el papel de centro mundial de poder” (FURTADO, 1993, p. 11). Las hipótesis y sus comprobaciones, sobre el comportamiento del sistema de poder estadounidense eran necesarias para explicar lo que estaba sucediendo en América Latina. De nuevo, es una lectura de la economía mundial y de las relaciones de fuerza que la atraviesan que hace parte de la explicación de la dinámica económica y social en América Latina.

En años recientes, con el avance de la globalización y la internacionalización de un reducido grupo de grandes empresas, el subdesarrollo conoce nuevas formas.

...les entreprises se globalisent, plus elles échappent à l'action régulatrice de l'Etat et plus elles tendent à śappuyer sur les marchés extérieurs pour croître. En même temps, les initiatives des entrepreneurs tendent à échapper au contrôle des instantes politiques. On revient ainsi au modèle du capitalisme original, dont la dynamique se fondant sur les exportations et sur les investissements à l'étranger” (FURTADO, 1998b, p. 171)

Esas grandes empresas toman sus decisiones de inversión y organizan sus actividades desde sus matrices, por lo que en el caso de gran 
cantidad de países son un elemento externo. Como se analiza en el texto, en los países de América Latina hay una creciente desarticulación en tanto el sistema económico depende de decisiones tomadas en el extranjero en aspectos fundamentales. En esas economías se profundiza la heterogeneidad social, la concentración del ingreso y la riqueza y las desigualdades sociales. Se mantiene bajo nuevas formas el subdesarrollo y bajo estas condiciones opera la economía mundial. Furtado concluye que es posible que durante un cierto tiempo el sistema capitalista no recupere su dinamismo no logre las tasas de creación de empleo de los años 1940-1970 y reanude la tarea de reducción de las desigualdades sociales, en particular en las economías periféricas o en las economías subdesarrolladas.

En años pasados, en varios países de América del Sur gobiernos resultado de procesos electorales en un cuadro de avances democráticos realizaron cambios en materia de política económica, se alejaron de la agenda de propuestas de los actores sociales que defienden el Consenso de Washington y avanzaron en la creación de instituciones para reducir la desigualdad social. La recuperación del espacio nacional en la toma de decisiones y en la conducción de la dinámica económica ha sido parte de los cambios propuestos. Se estaba creando una situación diferente en el ámbito de la economía internacional. Sin embargo, no necesariamente con métodos democráticos, se impidió la continuidad de esos gobiernos en varios países de la región. Las políticas ejecutadas inmediatamente por los nuevos gobiernos han sido favorables a las grandes empresas, en particular a la plena recuperación de la dinámica económica por empresas con matriz en el exterior. En el texto intitulado L’impératif technologique et les inégalités sociales, Furtado (1998b, p. 171) concluye: "Reste à savoir comment se présentera le découpage politique d'un monde où les grandes entreprises qui con- 
trôlent la création de nouvelles techniques sont la force dominante”

\section{Referencias}

DE BERNIS, Gerard. Furtado et l'économie mondiale. Cahiers du Brésil contemporain, Paris : Maison des Sciences de l'Homme, Centre de Recherches sur le Brésil Contemporain et Institut des Hautes Etudes d'Amérique Latine, no. 33/34, p. 59-67, 1998.

IV CUMBRE DE LAS AMERICAS. Declaración de Mar de Plata 2005. Mar de Plata, Argentina, diciembre, 2005. Disponible en: www.summit-americas.org. Accedido: 16 de mayo 2018.

FAJNZYLBER, Fernando y MARTÍNEZ TARRAGÓ. Trinidad, Las empresas transnacionales. México: Fondo de Cultura Económica. 1976.

FURTADO, Celso. Desarrollo y Subdesarrollo. Buenos Aires: Editorial Universitaria de Buenos Aires, 1964 [Edición original: Desenvolvimento e subdesenvolvimento. Rio de Janeiro: Editora Fundo de Cultura, 1961].

. La hegemonía de los USA y América Latina. Madrid: Editorial Cuadernos para el Diálogo, 1971.

. Teoría y política del desarrollo económico (quinta edición en español, corregida y aumentada). México: Siglo XXI Editores, 1974 [Edición original: Teoria e política do desenvolvimento econômico. São Paulo: Companhia Editora Nacional, 1967].

. Los vientos del cambio. México: Fondo de Cultura Económica, 1993. [Edición original: Os ares do mundo. São Paulo: Paz e Terra, 1991].

. O Capitalismo Global. São Paulo: Paz e Terra, 1998a.

. L’impératif technologique et les inégalités sociales. Cahiers du Brésil contemporain. Paris : Maison des Sciences de l'Homme, Centre de Recherches sur le Brésil Contemporain et Institut des Hautes Etudes d'Amérique Latine, no. 33/34p. 169-171, 1998 b.

. La economía latinoamericana. Formación histórica y problemas contemporáneos (vigésimo cuarta edición en español con base en la octava edición en español, corregida y aumentada, 1976). México: Siglo XXI Editores, 2001. [Edición original: Formação econômica da América Latina (edición 
revisada). São Paulo: Companhia Editora Nacional, 1976].

. Retour à la vision globale de Perroux et Prebisch, Économie appliquée. Paris: Tome LIX, No 3, les Presses de l' ISMÉA, p. 13-22. septembre, 2006.

. Criatividade e dependência na civilização industrial. Edição definitiva. São Paulo: Companhia das Letras, 2008 [Edición original: Rio de Janeiro, Paz e Terra, 1978].

KIRCHNER, Néstor. Palabras en la inauguración de la IV Cumbre de las Américas. Mar de Plata, Argentina, noviembre, 2005. Disponible en: www.oas.org. Accedido: 16 de mayo 2018.

LICHTENSZTEJN, Samuel. La deuda externa, la disponibilidad del excedente y los proyectos democráticos actuales de América Latina, en: GONZÁLEZ CASANOVA, P. (coordinador). El Estado en América Latina. Teoría y Práctica. México: Siglo XXI Editores, 1990. p. 161-185.

UNCTAD. World Investment Report 2001. Promoting Linkages. New York and Geneva: United Nations, 2001.

. World Investment Report 2009. Transnational Corporations, Agricultural Production and Development. New York and Geneva: United Nations, 2009.

. World Investment Report 2013. Global Value Chains: Investment and trade for development. New York and Geneva: United Nations, 2013.

. World Investment Report 2017. Investment and the digital economy, New York and Geneva, United Nations, 2017.

VIDAL, Gregorio. Estado, crecimiento y desarrollo: algunos elementos sobre la experiencia mexicana. Iztapalapa Revista de Ciencias Sociales y Humanidades, México, núm. 38, año 16, p. 57-76, 1996.

. Privatizaciones, fusiones y adquisiciones. Las grandes empresas en América Latina. Barcelona: Anthropos Editorial. 2001.

. Privatizations in Latin America. In: ARESTIS, P.; SAWYER M. (editors). Critical Essays on the Privatization Experience. Hampshire, England: Palgrave Macmillan, 2009. p. 202-245.

. Economía y grandes empresas en México: ¿Qué cambió con el TLCAN?. In: CORREA E. y GAZOL A. (coordinadores). A 20 años del TLC. 
México: UNAM, 2015a, p. 265-293.

. Manufacturing, Industry and Growth in Mexico. International Journal of Political Economy, Philadelphia, Vol. 43. No. 4, Winter 2014-2015. p. 63-81, 2015b.

WILLIAMSON, John. Latin American Adjustment. How much has happened? Washington: Institute for International Economics, April. 1990. 


\begin{abstract}
:
This paper analyzes the role of the United States, specifically in relation to the dynamics of societies in Latin America and the actions of transnational corporations in the world economy. The above, framed by different problems that conditioned development. This paper highlights that the ideas of underdevelopment are a relevant contribution of Celso Furtado's studies, as they are presented within international economic and political relations. These are a critique of conventional theories of international trade. This perspective, it is argued, is still in force today, even taking into account globalization, the advancement of productive and financial internationalization and the deployment of transnational corporations.
\end{abstract}

Keywords: Underdevelopment; transnational corporations; international economy.

\title{
Resumen:
}

En el texto se analiza el papel de Estados Unidos, específicamente con relación a la dinámica de las sociedades en América Latina y las acciones de las empresas transnacionales en la economía mundial en particular en América Latina, frente al problema de la creación de las condiciones del desarrollo. Se destaca que la explicación del subdesarrollo es un aporte relevante en los estudios de Celso Furtado en tanto se presenta en el espacio de las relaciones económicas y políticas internacionales, como una crítica a las teorías convencionales del comercio internacional. Esa perspectiva conserva en la actualidad su plena vigencia, incluso teniendo en cuenta la globalización, el avance de la internacionalización productiva y financiera y el despliegue de las transnacionales.

Palabras-clave: Subdesarrollo; empresas transnacionales; economía internacional. 